\title{
Acoustic emission generated by granular soil-steel structure interaction
}

\author{
Alister Smith $^{1 *}$, Helen J. Heather-Smith², Neil Dixon ${ }^{3}$, James A. Flint ${ }^{4}$ and David Pennie ${ }^{5}$ \\ ${ }^{1 *}$ EPSRC Fellow and Lecturer in Civil Engineering Infrastructure, School of Architecture, Building and Civil \\ Engineering, Loughborough University, UK \\ Corresponding author: A.Smith10@lboro.ac.uk \\ ${ }^{2}$ Doctoral Researcher, School of Architecture, Building and Civil Engineering, Loughborough University, UK \\ ${ }^{3}$ Professor of Geotechnical Engineering, School of Architecture, Building and Civil Engineering, \\ Loughborough University, UK \\ ${ }^{4}$ Reader in Wireless Systems Engineering, School of Mechanical, Electrical and Manufacturing Engineering, \\ Loughborough University, UK \\ ${ }^{5}$ Undergraduate Civil Engineering Student, School of Architecture, Building and Civil Engineering, \\ Loughborough University, UK
}

\begin{abstract}
This study has established quantitative interpretation of acoustic emission (AE) generated by granular soil/steel structure interaction. This new knowledge will enable the evolution of soil/structure interaction behaviour to be interpreted from AE measurements. AE monitoring could now provide early warning of soil/structure system (e.g. buried pipelines, pile foundations and retaining structures) limit state failures in the field and enhance insights into element and physical model tests in the laboratory. Results from a programme of large direct-shear tests performed on granular soil/steel interfaces show that $A E$ generation is influenced by the normal effective stress, mobilised shearing resistance and shearing velocity. Compression-induced AE activity in granular soil/steel systems is negligible until the current stress conditions exceed the maximum that has been experienced in the past. Relationships have been quantified between $A E$ and normal effective stress, mobilised shearing resistance and shearing velocity, enabling quantitative interpretation of cyclic and accelerating soil/structure interaction behaviour from $\mathrm{AE}$ measurements.
\end{abstract}

\section{KEYWORDS}

deformation; geophysics; laboratory tests; monitoring; sands; soil/structure interaction 


\section{INTRODUCTION}

Soil/structure systems (e.g. buried pipelines, pile foundations and retaining structures) experience relative deformation between soil and structural elements from, for example, fault-rupture or landsliding intersecting a buried pipeline, operating temperature fluctuations causing cyclic axial displacements in buried pipelines, and cyclic loading of offshore monopiles. Such processes can lead to limit state (fatigue, serviceability and ultimate) failures that have catastrophic economic, environmental and societal consequences.

The mechanical behaviour of soil/structure interfaces is controlled by the soil's state (i.e. stress conditions and fabric), the stress path, and the surface properties of the soil and structural element (e.g. hardness, morphology and roughness) (Frost et al., 2002; Samanta et al., 2018; Saberi et al., 2019). Proportions of the energy dissipated during relative deformation between soil and structural elements are converted to heat and sound. The high-frequency $(>10 \mathrm{kHz})$ component of this sound energy is called acoustic emission (AE). AE is generated in soil/structure systems through a suite of mechanisms: inter-particle friction (rolling and sliding); friction at the interface between the soil and structural element; particle contact network rearrangement; degradation at particle asperities; degradation of the surface of the structural element; and particle crushing (Michlmayr \& Or, 2014; Smith \& Dixon, 2019).

Fundamental laboratory studies on the AE behaviour of soils carried out in the 1970s, 1980s and 1990s (e.g. Koerner et al., 1976; Koerner et al., 1978; Koerner et al., 1981; Tanimoto \& Nakamura, 1981; Koerner et al., 1984; Mitchell \& Romeril, 1984; Tanimoto \& Tanaka, 1986; Garga \& Chichibu, 1990; Shiotani \& Ohtsu, 1999) led to the following qualitative conclusions: well-graded soils generate more $A E$ than uniformly-graded soils; angular particles generate more $A E$ than rounded particles; AE amplitude increases with particle size; higher imposed stresses generates greater AE activity; and AE activity increases with imposed strain rate. Koerner et al. (1981) proposed the following qualitative guide for interpretation of $A E$ generated from soils deforming against a steel structural element: (i) no $A E$ indicates stability; (ii) moderate levels of $A E$ indicates marginal stability; and (iii) high levels of $A E$ indicates that the geotechnical system is unstable.

Recent studies have demonstrated the benefits of $A E$ monitoring in geotechnical engineering to quantify accelerating slope movements (e.g. Smith et al., 2014; Smith et al., 2017a) and interpret particle breakage behaviour under pile penetration (e.g. Mao et al., 2018). Smith \& Dixon (2019) developed a quantitative framework for interpreting the mechanical behaviour (e.g. mobilisation of peak shear strength and accelerating shear strains) of dense sands from AE measurements. Smith \& Dixon (2019) also demonstrated the influences of the fabric (i.e. orientation and distribution of particle contacts) and state (i.e. physical condition, including stresses and void ratio) of sands on $\mathrm{AE}$ generation.

The interpretation of soil/structure interaction-generated $A E$ has to date been qualitative. The objective of this study was to investigate the influence of stress level and deformation rate on the $\mathrm{AE}$ generated by granular soil/steel interaction. Quantifying the influence of these variables upon $A E$ generation will enable use of $A E$ monitoring to provide early warning of soil/structure system limit state failures in the field, for example, to detect, quantify and interpret accelerating deformation behaviour that accompanies progressive ground failure processes. Quantitative $\mathrm{AE}$ interpretation will also enhance insights into element and physical model tests in the laboratory.

\section{METHODOLOGY}

\section{Apparatus}

A Wille Geotechnik automatic large $(300 \times 300 \mathrm{~mm}$ constant cross-sectional area) direct-shear apparatus (ADS-300) was used and configured for soil/steel interaction testing with an AE sensor coupled to the steel plate as shown in Figure 1. This apparatus allows vertical displacement of the soil specimen while maintaining a constant normal stress, enabling investigation of volume change 
behaviour (e.g. contraction and dilation). This apparatus also allowed the application of a range of shearing velocities and cyclic behaviours. The base of the top box was positioned $0.6 \mathrm{~mm}$ above the steel plate to minimise extrusion of soil during testing.

\section{Materials}

Quartz Leighton Buzzard sand (LBS) was selected for this investigation as its mechanical behaviour has been studied extensively in the literature (e.g. Cavarretta et al., 2011; Senetakis et al., 2013; Dixon \& Smith, 2019). Two poorly-graded size fractions were selected to enable investigation of the influence of particle size on $A E$ generation, while removing, as far as is practically possible for a natural sand, mineralogy, shape, surface roughness and inter-particle friction as variables from the study. The physical properties of the LBS are shown in Table 1 and their particle size distributions are shown in Figure 2.

The structural element was a $3 \mathrm{~mm}$ thick mild steel plate, which was fixed atop the bottom box using bolts and supported by spacer blocks. The plate surface was relatively smooth and uncorroded and had an initial roughness average (i.e. the arithmetic average of the absolute values of the profile heights over the evaluation length), $R_{\mathrm{a}}$, of $0.85 \mu \mathrm{m}$ in the shearing direction and $0.87 \mu \mathrm{m}$ perpendicular to shearing (reported values are the average of $R_{\mathrm{a}}$ measurements taken from 8 different, consistent positions). Roughness progressively increased following each test to final values of $1.70 \mu \mathrm{m}$ in the shearing direction and $2.66 \mu \mathrm{m}$ perpendicular to shearing.

\section{Testing procedure}

A summary of the direct-shear tests performed in this study is shown in Table 2. Moderate compaction was achieved by tamping in $25 \mathrm{~mm}$ high layers to an approximate total height of 75 $\mathrm{mm}$ and an approximate relative density, $D_{\mathrm{r}}$, of $50 \%$ for LBS $0.5-2.0$ and $65 \%$ for LBS $2.0-3.35$ (i.e. medium dense and equal compaction effort for both sands). The LBS 2.0-3.35 specimen in Test 8 was prepared by pluviation (i.e. loose, $D_{\mathrm{r}}$ of $25 \%$ ). Compression was performed by increasing the normal stress at a constant rate of approximately $30 \mathrm{kPa}$ per minute until the target stress was achieved. Shearing was performed displacement-controlled. Applied test condition ranges were: normal stresses from 50 to $300 \mathrm{kPa}$ (i.e. equivalent to structural elements between approximately 3 and $20 \mathrm{~m}$ below ground level, such as buried pipelines and pile foundations), shearing velocities from 0.1 to $5 \mathrm{~mm} / \mathrm{min}$, and cyclic shearing displacement amplitudes from 1 to $27 \mathrm{~mm}$. Cyclic interface shear behaviour is relevant to buried pipelines experiencing operating temperature fluctuations that cause cyclic axial displacements and offshore monopile foundations experiencing cyclic loading from wave and wind actions.

\section{Acoustic emission measurements}

A band-pass filter was used to constrain the measured $A E$ to within the frequency range of 10-100 $\mathrm{kHz}$. Filtering signals below $10 \mathrm{kHz}$ is essential to remove extraneous low-frequency environmental noise that could be generated in a laboratory by machinery or in the field by construction activity and traffic. The focus of this investigation was soil/steel frictional interactions; particle damage and fracturing were minimised through application of relatively low effective confining stress (i.e. $\leq 300$ $\mathrm{kPa}$ ). Mao \& Towhata (2015) found that particle crushing has a much higher frequency content $(>100 \mathrm{kHz})$ than inter-particle friction and particle rearrangement $(<100 \mathrm{kHz})$. It is notable that particle damage was minimal in the experiments reported here (confirmed through post-test particle size distributions), and hence filtering above $100 \mathrm{kHz}$ was appropriate for this study.

The AE sensor was connected to the steel plate using a magnetic holder (position shown in Figure 1). The sensor was a MISTRAS R3a piezoelectric transducer, which is sensitive over the frequency range of $0-100 \mathrm{kHz}$ and has a resonant frequency of $30 \mathrm{kHz}$. The sensor converts the mechanical $A E$ to a voltage waveform that can be processed. 
The $A E$ measurement system was a bespoke setup comprising a pre-amplifier ( $20 \mathrm{~dB}$ gain), a main amplifier ( $3 \mathrm{~dB}$ gain), an analogue-to-digital converter with $2 \mathrm{MHz}$ sampling frequency, and a laptop with a LabView program to condition, process and record the AE waveform. The two amplifiers were used to improve the signal-to-noise ratio. The Nyquist frequency is the minimum sampling rate required to digitally reconstruct the signal without introducing errors, which is twice the highest frequency present in the signal and hence the $2 \mathrm{MHz}$ sampling rate was sufficient to reconstruct the 10-100 kHz AE waveforms.

Two key AE parameters of interest are ring-down counts (RDC) and b-value. RDC per unit time are the number of times the AE waveform crosses a programmable threshold level (set to $0.01 \mathrm{~V}$ in this study, above background environmental and electronic noise as shown in Figure 3) within a predefined time interval and are a measure of the AE signal energy. RDC were recorded at 10second intervals and subsequently converted to equivalent per minute values. RDC measurements are presented for all tests and exemplar $b$-value measurements are presented for specific tests. The $b$-value is a convenient way to describe the AE amplitude distribution in a single value (Pollock, 1973). When the AE waveform is dominated by low amplitude events the $b$-value is large. As the proportion of higher amplitude events increases, indicating an increase in energy, the $b$ value reduces. The $b$-value was computed at 30 -second intervals using Equations 1 and 2 .

$\log N=c-b m$

$m=\log A$

where $A$ is the amplitude, $m$ is a log-scale measure termed magnitude, $N$ is the number of $A E$ events with magnitude greater than $m, c$ is the point that the $\log (N)$ vs. $m$ relationship intersects the $y$-axis, and the coefficient $b$ ( $b$-value) is the negative slope of the $\log (N)$ vs. $m$ relationship.

\section{RESULTS}

\section{Compression}

Figure 4 shows results from compression tests performed on LBS 0.5-2.0 (tests 1-3). Space precludes inclusion of time series measurements from all tests; however, the general trends in behaviour were the same, and results from all compression tests (tests 1-3 and 9-12) are compared in relation to the change in normal effective stress in Figure 5.

The cumulative RDC generated was proportional to the change in normal effective stress and they followed comparable trends with time. The $b$-value measurements reduced, indicating a greater proportion of higher magnitude events, as the normal stress was increasing, and the specimen volume was reducing. The $b$-values then gradually increased again when negligible further stress or volume change took place.

The linear regression in Figure 4e shows that approximately $314 \mathrm{RDC}$ were generated per $1 \mathrm{kPa}$ change in normal effective stress. Figure 5 shows that both LBS 0.5-2.0 and LBS 2.0-3.35 generated comparable magnitudes of $A E$ for a unit change in normal effective stress in compression; LBS 0.5-2.0 generated marginally greater levels of AE because it had lower initial relative density and experienced greater volume reduction, and hence particle-particle interactions. The power relationships shown in Figure 5 best describe the data because both normal effective stress and density (i.e. number of particle contacts per particle) increase during compression, having a combined effect on AE generation (as described in Smith \& Dixon (2019)).

Figure 6 shows results from load-unload-reload cycles of normal stress on LBS 2.0-3.35 (tests 7 and 8), which demonstrates that the Kaiser Effect (Lavrov, 2003) is experienced by soil compressing against structural elements (i.e. AE activity is negligible until the current stress conditions exceed the maximum that has been experienced in the past) and that looser soils 
generate greater AE per unit change in normal stress as they experience greater volume change during compression. Imposed unload and reload stages of normal stress were $25 \mathrm{kPa}$ and $75 \mathrm{kPa}$, respectively.

\section{Shearing}

Figure 7 shows results from tests 9-12 (LBS 2.0-3.35) to demonstrate the influence of stress level on $A E$ generation. Shearing resistance was rapidly mobilised and then remained relatively constant thereafter. This shear stress versus shear displacement behaviour is characteristic of interface shear between steel and granular media (e.g. Ho et al., 2011). Measured AE rates were proportional to mobilised shearing resistance. Figure $7 e$ shows the average $A E$ rate (calculated following full mobilisation of shearing resistance) versus applied normal effective stress relationship for these tests, which results in an $\mathrm{R}^{2}$ value of 0.96 from linear regression.

Results from test 13 are shown in Figure 8. Stepped increases in shear velocity were imposed during the test to investigate the $A E$ response to accelerating deformation behaviour. Average $A E$ rate and $b$-value measurements, calculated during each constant shear velocity stage, are plotted against shear velocity in Figure $8 \mathrm{~d}$. The $b$-value measurements rapidly reduced during the initial mobilisation of shearing resistance and then continued to reduce but at a significantly lower rate, inversely proportionally to imposed shear velocity. The AE rate measurements increased proportionally with imposed shear velocity. Systematic curve fitting resulted in a polynomial curve best describing the $A E$ rate versus shear velocity relationship over the range of data examined $\left(R^{2}\right.$ of 0.99 ) and a power curve best describing the $b$-value versus shear velocity relationship ( $R^{2}$ of 0.93). Observed periodic extrusion of sand at the interface is likely to have contributed to the continued negative vertical displacement and fluctuating shear stress.

The combined influence of stress level and shear velocity on AE generation is quantified in Figure 9. To obtain the gradients of linear $A E$ rate versus normal stress relationships, average $A E$ rates (following full mobilisation of shearing resistance) were calculated during tests and test stages where the imposed shearing velocity was constant (tests 1-6 and 9-12). Figure 9 shows that for LBS 0.5-2.0, the gradient of the AE rate versus normal stress relationship increases linearly proportionally with imposed shearing velocity. The gradient of the $A E$ rate versus normal stress relationship obtained at a shearing velocity of $2 \mathrm{~mm} / \mathrm{min}$ for LBS 2.0-3.35 (i.e. triangle data point) is 1.96 times greater than that for LBS $0.5-2.0$ at the same shearing velocity. Smith \& Dixon (2019) showed that soil-generated AE activity increased with particle size in shearing. Greater particleparticle and particle-steel contact stresses (i.e. approximately $1 / 7$ th of the particles in contact with the steel interface) were the cause of higher levels of AE generated by LBS 2.0-3.35 than LBS 0.52.0 at the same rate of shearing.

Figure 10 shows results from shear displacement cycles performed on LBS 2.0-3.35 (test 14). Figure 10a shows the amplitudes of imposed displacement cycles. Although dilative behaviour took place during the shear strength mobilisation phases of each displacement cycle, the specimen experienced net volume reduction (i.e. Figure 10b shows $4 \mathrm{~mm}$ accumulated negative vertical displacement). Shear stress is plotted against shear displacement in Figure 10c, which shows that within each cycle the differences between forward and reverse mobilised shearing resistances were minimal. Figure $10 \mathrm{~d}$ shows comparable hysteretic behaviour occurred in the AE rate measurements, which were defined as negative during the reverse phases of each displacement cycle to allow graphical visualisation. These $A E$ rate measurements are plotted against shear stress in Figure 10e, which demonstrate that $A E$ monitoring could be used to interpret mobilised shearing resistance. The magnitude of $A E$ rates measured during the forward phase were marginally greater than those measured during the reverse phase of each displacement cycle, though trends in behaviour were comparable. 


\section{DISCUSSION AND CONCLUSIONS}

This study has established quantitative interpretation of $A E$ generated by granular soil/steel interaction. This new knowledge will enable AE monitoring to provide early warning of soil/structure system (e.g. buried pipelines, pile foundations and retaining structures) limit state failures in the field. It also demonstrates that innovated $A E$ instrumentation and measurement can enhance insights into element and physical model tests in the laboratory.

Interface friction angles obtained from a programme of large direct-shear tests on granular soil/steel interfaces of $29.1^{\circ}$ and $30.3^{\circ}$ for LBS 0.5-2.0 and LBS 2.0-3.35, respectively, were consistent with mechanical sand/steel interface behaviour reported in the literature (e.g. Ho et al., 2011).

The results show that granular soil/steel interaction-generated $A E$ is proportional to the normal effective stress, mobilised shearing resistance, shearing velocity and soil properties. Loose soils generate greater $A E$ in compression than dense soils as they experience greater volume reduction, and larger particles generate higher levels of $A E$ in shearing as greater particle-particle and particle-steel contact stresses develop per unit area of the interface.

This has been the first study to measure $A E$ rates and $b$-values from direct-shear testing of granular soil/steel interaction. New relationships have been quantified between AE parameters (AE rates and $b$-values) and normal effective stress, mobilised shearing resistance and shearing velocity, enabling interpretation of cyclic and accelerating soil/structure interaction behaviour from $\mathrm{AE}$ measurements.

An example of how $A E$ rate (RDC per unit time) measurements could be used to interpret accelerating deformation behaviour is shown in Figure 11. Figure 11b illustrates how the current $A E$ rate $\left(A E_{t}\right)$ minus the preceding $A E$ rate $\left(A E_{t-1}\right)$ and normalised by the initial $A E$ rate measurement $\left(A E_{t=\xi}\right)$ can be used to trigger warnings based on deformation rates.

The study has also extended knowledge to demonstrate that compression-induced AE activity in soil/structure systems is negligible until the current stress conditions exceed the maximum that has been experienced in the past due to the Kaiser Effect; the existence of the Kaiser Effect has been demonstrated in soil bodies in previous studies (e.g. Koerner et al., 1981; Smith \& Dixon, 2019).

AE transmitted into structural elements (e.g. pipes and piles) propagate as guided waves. A framework to quantify the magnitude of attenuation experienced by $A E$ in soil/structure systems is enabling sensor spacings to be selected for a range of applications and source localisation methodologies to be developed (Smith et al., 2017b; Heather-Smith et al., 2018; Smith et al., 2019). Development of a continuous, real-time AE monitoring system that can be distributed at discrete locations along buried infrastructure systems (e.g. pipelines, foundations and retaining structures) to sense soil/structure interaction could provide early warnings of adverse behaviour to enable targeted and timely interventions. Warning criteria could be established to trigger decision makers to inspect the assets and prioritise maintenance and remediation or terminate service to prevent catastrophic consequences.

\section{ACKNOWLEDGEMENTS}

Special thanks are due to Lewis Darwin, technician, for supporting the testing programme and to undergraduate James Wordingham who conducted preliminary direct-shear testing. Alister Smith gratefully acknowledges the support of an EPSRC Fellowship (Listening to Infrastructure, EP/P012493/1). Helen Heather-Smith gratefully acknowledges the support of an EPSRC and Loughborough University funded PhD studentship. 


\section{REFERENCES}

Cavarretta, I., Rocchi, I., \& Coop, M. R. (2011). A new interparticle friction apparatus for granular materials. Canadian Geotechnical Journal, 48(12), 1829-1840.

Frost, J. D., DeJong, J. T., \& Recalde, M. (2002). Shear failure behavior of granular-continuum interfaces. Engineering Fracture Mechanics, 69(17), 2029-2048.

Garga, V. K. \& Chichibu, A. (1990). A study of AE parameters and shear strength of sand. Progress in Acoustic Emission, 129, 136.

Heather-Smith, H. J., Smith, A., Dixon, N., Flint, J. A., \& Wordingham, J. (2018). Monitoring buried infrastructure deformation using acoustic emissions. 9th European Workshop on Structural Health Monitoring, July 10-13, 2018, Manchester, United Kingdom

Ho, T. Y. K., Jardine, R. J., \& Anh-Minh, N. (2011). Large-displacement interface shear between steel and granular media. Géotechnique, 61(3), 221.

Koerner, R. M., Lord Jr, A. E., Mccabe, W. M. \& Curran, J. W. (1976). Acoustic emission behavior of granular soils. Journal of Geotechnical and Geoenvironmental Engineering, 102(ASCE\# 12239 Proceeding).

Koerner, R. M., Lord Jr, A. E. \& McCabe, W. M. (1978). Acoustic emission monitoring of soil stability. Journal of Geotechnical and Geoenvironmental Engineering, 104(ASCE 13753).

Koerner, R. M., McCabe, W. M. \& Lord, A. E. (1981). Acoustic emission behavior and monitoring of soils. In Acoustic emissions in geotechnical engineering practice (eds V. P. Drnevich and R. E. Gray), ASTM STP 750, pp. 93-141. West Conshohocken, PA, USA: ASTM International.

Koerner, R. M., Lord Jr, A. E. \& Deutsch, W. L. (1984). Determination of prestress in granular soils using AE. Journal of Geotechnical Engineering, 110(3), 346-358.

Lavrov, A. (2003). The Kaiser effect in rocks: principles and stress estimation techniques. International Journal of Rock Mechanics and Mining Sciences, 40(2), 151-171.

Mao, W., \& Towhata, I. (2015). Monitoring of single-particle fragmentation process under static loading using acoustic emission. Applied Acoustics, 94, 39-45.

Mao, W., Aoyama, S., \& Towhata, I. (2018). Feasibility study of using acoustic emission signals for investigation of pile spacing effect on group pile behavior. Applied Acoustics, 139, 189-202.

Michlmayr, G. \& Or, D. (2014). Mechanisms for acoustic emissions generation during granular shearing. Granular Matter, 16(5), 627-640.

Mitchell, R. J. \& Romeril, P. M. (1984). Acoustic emission distress monitoring in sensitive clay. Canadian Geotechnical Journal, 21(1), 176-180.

Pollock, A. A. (1973). Acoustic emission-2: acoustic emission amplitudes. Non-destructive testing, 6(5), 264-269.

Saberi, M., Annan, C. D., \& Konrad, J. M. (2019). Implementation of a soil-structure interface constitutive model for application in geo-structures. Soil Dynamics and Earthquake Engineering, 116, 714-731.

Samanta, M., Punetha, P., \& Sharma, M. (2018). Influence of surface texture on sand-steel interface strength response. Géotechnique Letters, 8(1), 40-48. 
Senetakis, K., Coop, M. R., \& Todisco, M. C. (2013). The inter-particle coefficient of friction at the contacts of Leighton Buzzard sand quartz minerals. Soils and Foundations, 53(5), 746-755.

Shiotani, T. \& Ohtsu, M. (1999). Prediction of slope failure based on AE activity. In Acoustic emission: standards and technology update. ASTM International.

Smith, A., \& Dixon, N. (2019). Acoustic emission behaviour of dense sands. Géotechnique, 10.1680/jgeot.18.P.209

Smith, A., Dixon, N., Meldrum, P., Haslam, E. \& Chambers, J. (2014). Acoustic emission monitoring of a soil slope: Comparisons with continuous deformation measurements. Géotechnique Letters, 4(4), 255-261.

Smith, A., Dixon, N. \& Fowmes, G. (2017a). Early detection of first-time slope failures using acoustic emission measurements: large-scale physical modelling. Géotechnique, 67(2), 138-152.

Smith, A., Dixon, N., \& Fowmes, G. (2017b). Monitoring buried pipe deformation using acoustic emission: quantification of attenuation. International Journal of Geotechnical Engineering, 11(4), 418-430.

Smith, A., Moore, I. D., \& Dixon, N. (2019). Acoustic Emission Sensing of Pipe-Soil Interaction: Full-scale Pipelines Subjected to Differential Ground Movements. Journal of Geotechnical and Geoenvironmental Engineering. 10.1061/(ASCE)GT.1943-5606.0002185

Tanimoto, K. \& Nakamura, J. (1981). Studies of Acoustic Emission in Soils. In Acoustic Emissions in Geotechnical Engineering Practice, ASTM STP 750, V. P. Drnevich and R. E. Gray, Eds., American Society for Testing and Materials, pp. 164-173.

Tanimoto, K. \& Tanaka, Y. (1986). Yielding of soil as determined by acoustic emission. Soils and foundations, 26(3), 69-80.

Zheng, J. \& Hryciw, R. D. (2015). Traditional soil particle sphericity, roundness and surface roughness by computational geometry. Géotechnique, 65(6), 494-506. 


\section{TABLES}

Table 1. Physical properties of the quartz Leighton Buzzard Sand (LBS)

\begin{tabular}{|c|c|c|}
\hline Property & LBS 0.5-2.0 & LBS 2.0-3.35 \\
\hline Particle size range: $\mathrm{mm}$ & $0.5-2.0$ & $2.0-3.35$ \\
\hline Median particle size, $d_{50}: \mathrm{mm}$ & 1.21 & 2.65 \\
\hline Coefficient of uniformity, $C_{u}$ & 1.943 & 1.344 \\
\hline Coefficient of curvature, $C_{\mathrm{c}}$ & 0.948 & 0.964 \\
\hline Minimum void ratio, $e_{\min }$ & 0.492 & 0.517 \\
\hline Maximum void ratio, $e_{\max }$ & 0.679 & 0.690 \\
\hline Specific gravity of particles, $G_{s}$ & 2.67 & 2.67 \\
\hline Roundness of particles $\ddagger$ & $\begin{array}{c}0.31-0.66 \\
(\text { mean }=0.51)\end{array}$ & $\begin{array}{c}0.18-0.73 \\
(\text { mean }=0.48)\end{array}$ \\
\hline Sphericity of particles ${ }^{\ddagger}$ & $\begin{array}{c}0.42-0.96 \\
(\text { mean }=0.69)\end{array}$ & $\begin{array}{c}0.36-0.86 \\
(\text { mean }=0.63)\end{array}$ \\
\hline Critical state friction angle, $\phi_{\text {crit }}^{\prime}$ : degrees ${ }^{*}$ & 33.5 & 34.0 \\
\hline Soil/steel interface friction angle, $\delta^{\prime}:$ degrees ${ }^{\dagger}$ & 29.1 & 30.3 \\
\hline
\end{tabular}

$\ddagger$ The reported particle shape parameters (range and mean) are the result of measurements from 40 particles: roundness and sphericity (circle ratio) were computed using two-dimensional microscope images and the method described in Zheng \& Hryciw (2015).

* The reported critical state friction angles were obtained from triaxial testing described in Smith \& Dixon (2019).

† The interface friction parameters were obtained from interface shearing tests performed in this study.

Table 2. Summary of the direct-shear tests performed in this study

\begin{tabular}{|c|c|c|c|c|c|}
\hline Test no. & Material* & Test type $^{\dagger}$ & $\begin{array}{c}\text { Soil } \\
\text { compaction }{ }^{\ddagger}\end{array}$ & $\sigma_{n}^{\prime}(k P a)$ & $\begin{array}{l}\text { Shear velocity } \\
\text { (mm/min) }\end{array}$ \\
\hline 1 & LBS 0.5-2.0 & CDR & Moderate & 75 & 1 \\
\hline 2 & LBS 0.5-2.0 & CDR & Moderate & 150 & 1 \\
\hline 3 & LBS $0.5-2.0$ & CDR & Moderate & 225 & 1 \\
\hline 4 & LBS 0.5-2.0 & ADR & Moderate & 75 & 0.5 to 2 \\
\hline 5 & LBS 0.5-2.0 & ADR & Moderate & 150 & 0.5 to 2 \\
\hline 6 & LBS 0.5-2.0 & ADR & Moderate & 225 & 0.5 to 2 \\
\hline 7 & LBS 2.0-3.35 & LUR & Moderate & 300 & - \\
\hline 8 & LBS 2.0-3.35 & LUR & None & 300 & - \\
\hline 9 & LBS 2.0-3.35 & CDR & Moderate & 50 & 2 \\
\hline 10 & LBS 2.0-3.35 & CDR & Moderate & 150 & 2 \\
\hline 11 & LBS 2.0-3.35 & CDR & Moderate & 200 & 2 \\
\hline 12 & LBS 2.0-3.35 & CDR & Moderate & 300 & 2 \\
\hline 13 & LBS 2.0-3.35 & ADR & Moderate & 150 & 0.1 to 5 \\
\hline 14 & LBS 2.0-3.35 & SDC & Moderate & 150 & \pm 2 \\
\hline
\end{tabular}

* Material identified using the size range shown in Table 1.

† Constant Displacement Rate (CDR), Accelerating Displacement Rate (ADR), Load-Unload-Reload (LUR), and Shear Displacement Cycles (SDC).

Note: The soils were prepared and tested dry. 


\section{FIGURES}

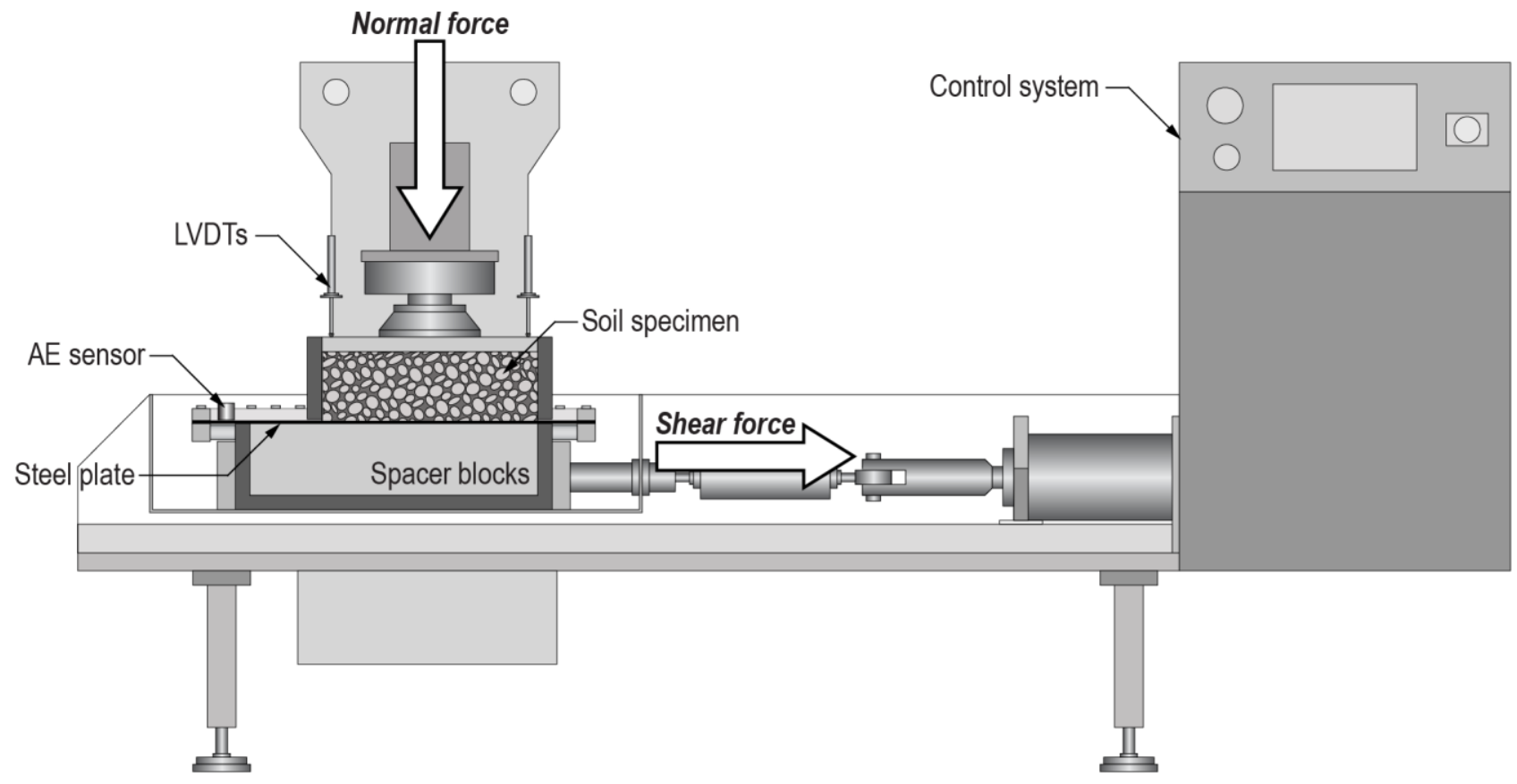

Figure 1. Schematic diagram of the Wille Geotechnik automatic large (300 x $300 \mathrm{~mm}$ crosssectional area) direct shear apparatus (ADS-300) configured for soil/steel interaction testing with an $A E$ sensor coupled to the upper surface of the steel plate

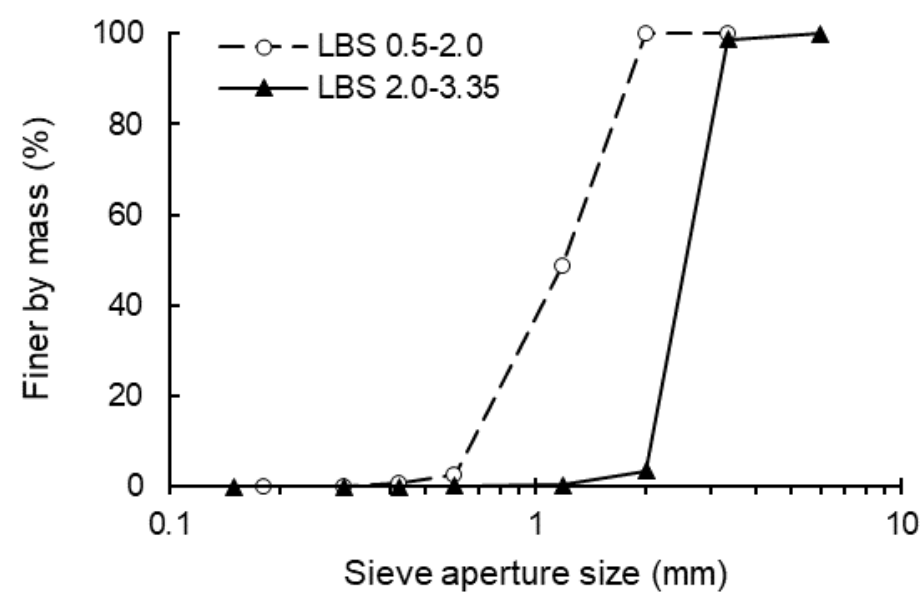

Figure 2. Particle size distributions of the quartz Leighton Buzzard sand 


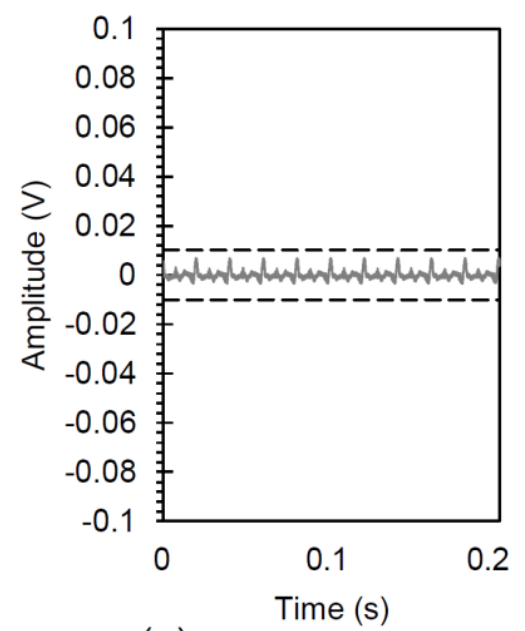

(a)

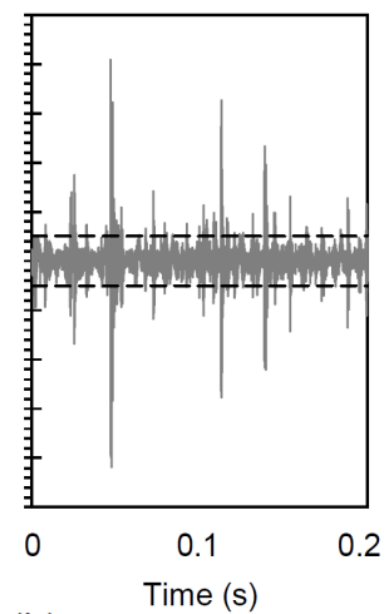

(b)

Figure 3. Example waveforms recorded using the AE measurement system showing the $0.01 \mathrm{~V}$ threshold level: (a) background environmental and electronic noise; (b) during soil deformation (after Smith \& Dixon (2019)) 
(a)

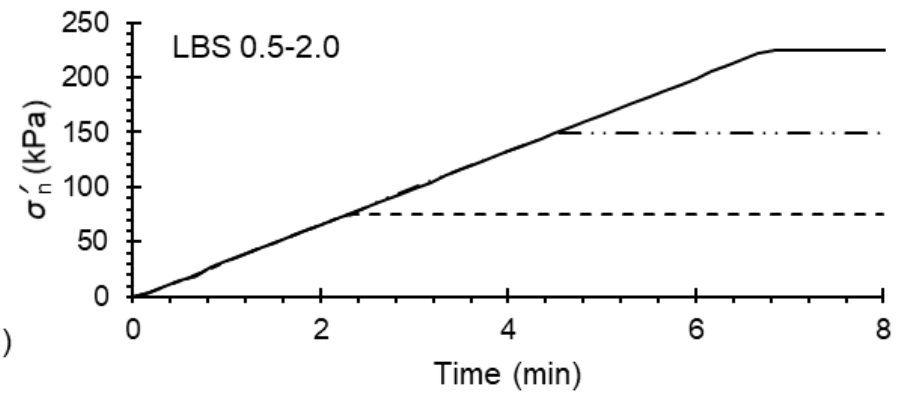

(b)
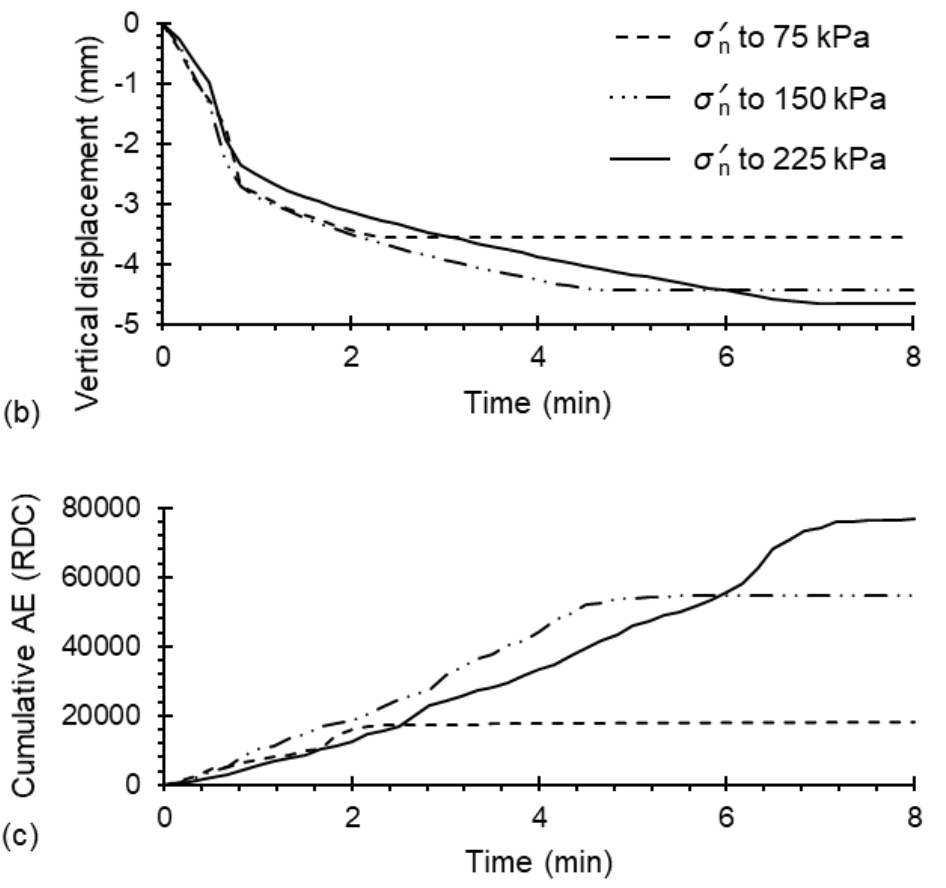

(d)
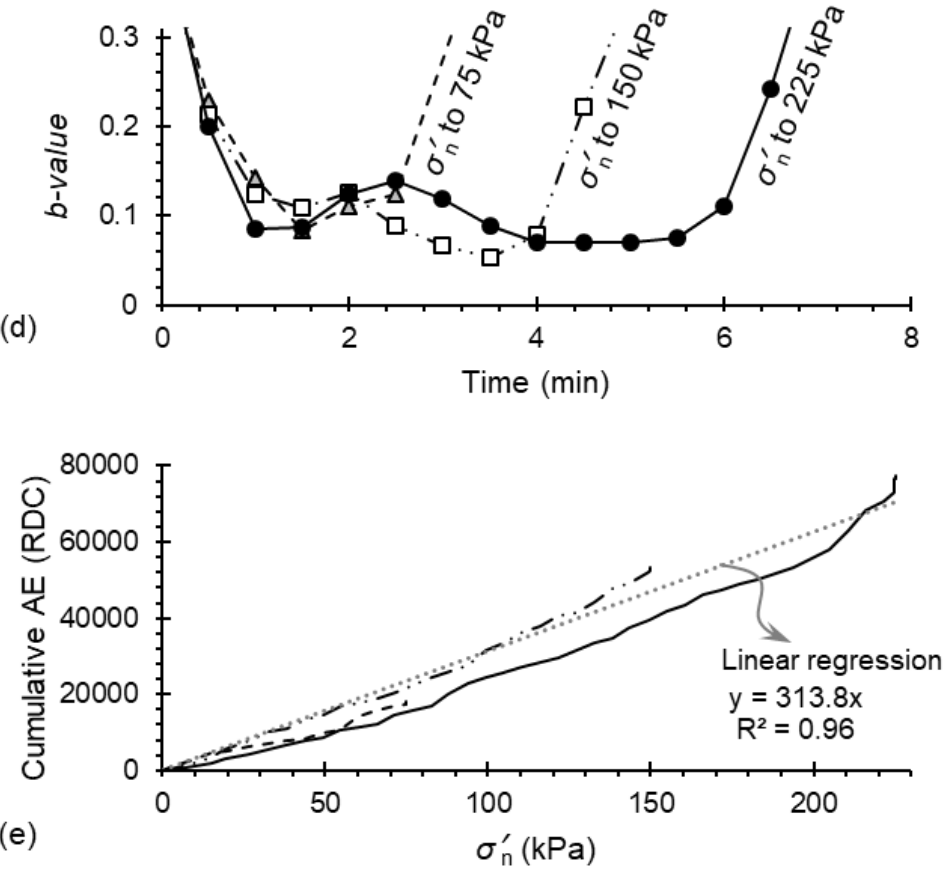

Figure 4. Results from compression tests to normal effective stresses of 75,150 and $225 \mathrm{kPa}$ performed on LBS 0.5-2.0 (tests 1-3): (a) normal effective stress plotted against time; (b) vertical displacement plotted against time (settlement is shown as negative); (c) cumulative AE plotted against time; (d) $b$-value plotted against time; and (e) cumulative AE plotted against normal effective stress 


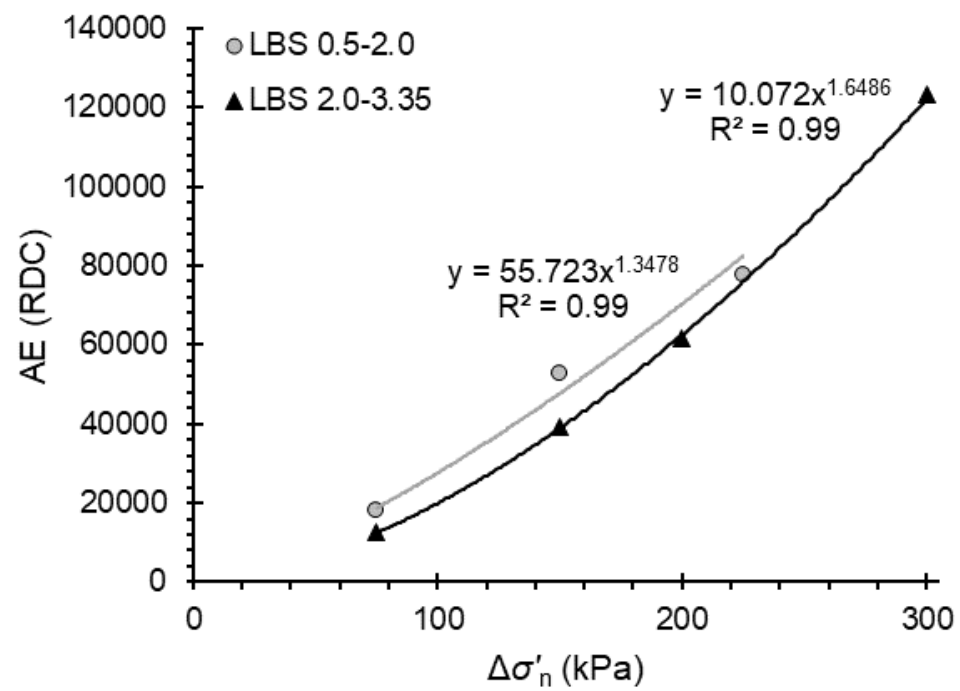

Figure 5. Results from compression tests performed on LBS 0.5-2.0 and LBS 2.0-3.35 (tests 1-3 and 9-12): total generated $A E$ plotted against the change in normal effective stress 

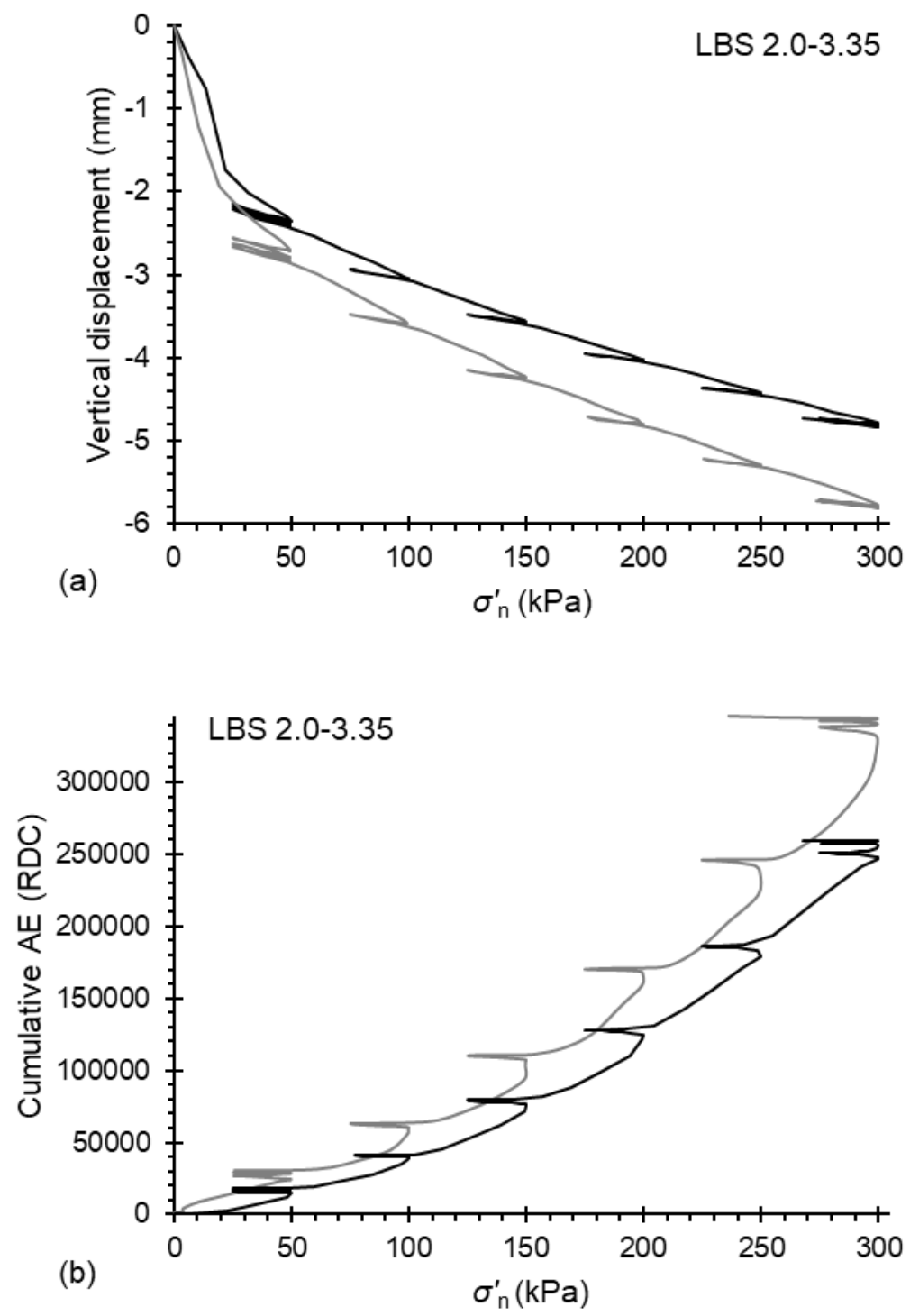

Figure 6. Results from load-unload-reload compression tests performed on LBS 2.0-3.35 (tests 7 and 8): (a) vertical displacement plotted against normal effective stress (settlement is shown as negative); and (b) cumulative AE plotted against normal effective stress. Note the black lines show test 7 (i.e. medium dense) and the grey lines show test 8 (i.e. loose) 

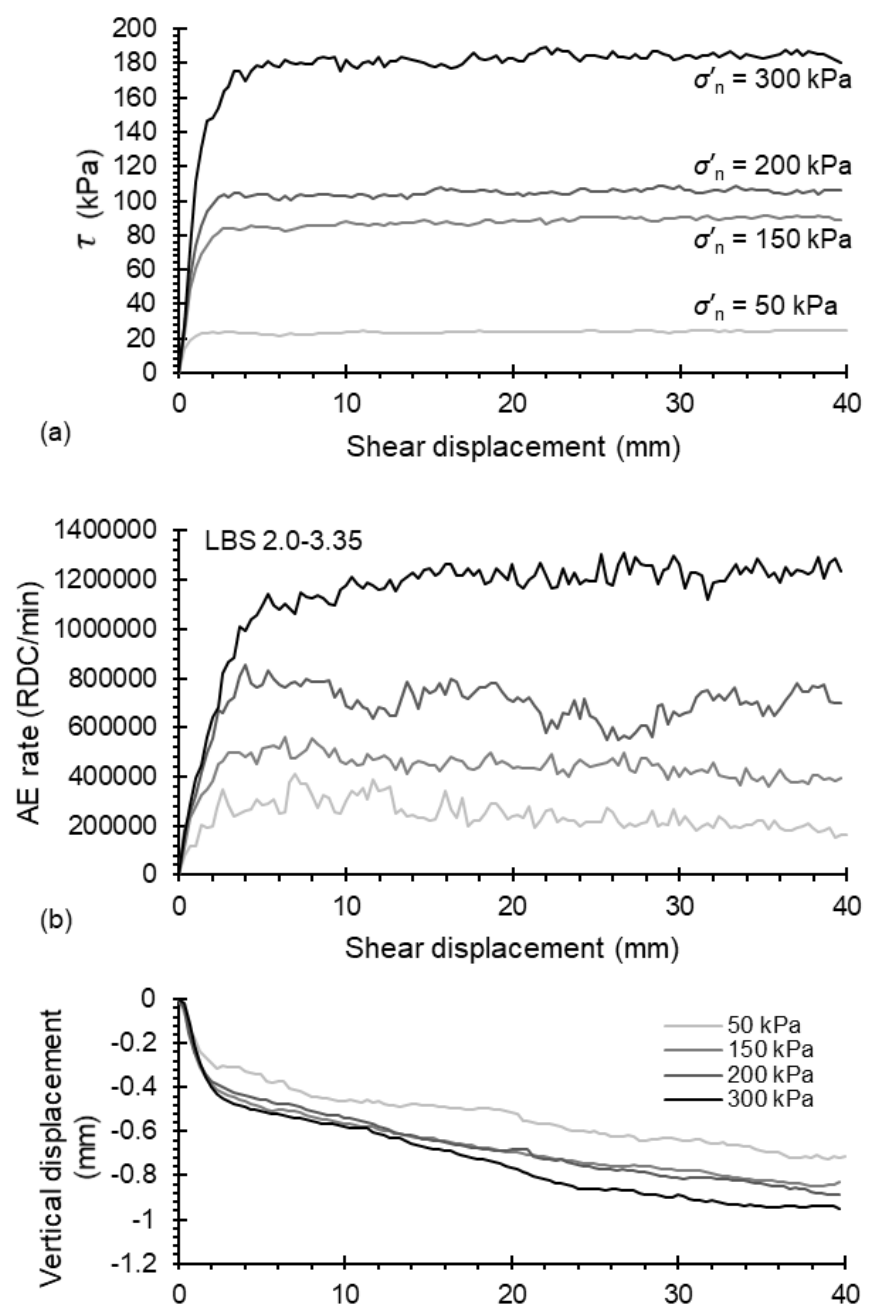

(c) Shear displacement $(\mathrm{mm})$

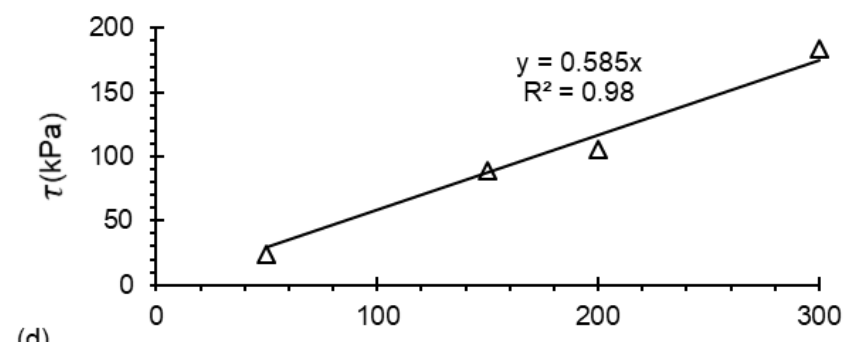

(d)

$$
\sigma_{\mathrm{n}}^{\prime}(\mathrm{kPa})
$$

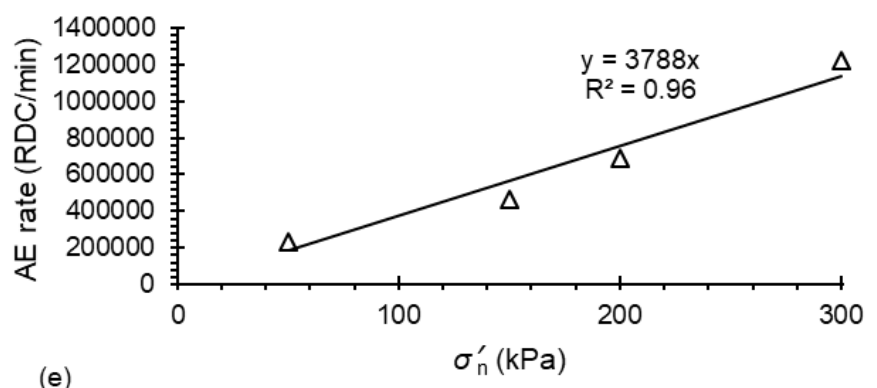

Figure 7. Results from shearing tests performed on LBS 2.0-3.35 (tests 9-12): (a) shear stress plotted against shear displacement; (b) AE rate plotted against shear displacement; (c) vertical displacement plotted against shear displacement; (d) shear stress (average of measurements taken after $15 \mathrm{~mm}$ of shear displacement) plotted against normal effective stress; and (e) AE rate (average of measurements taken after $15 \mathrm{~mm}$ of shear displacement) plotted against normal effective stress 


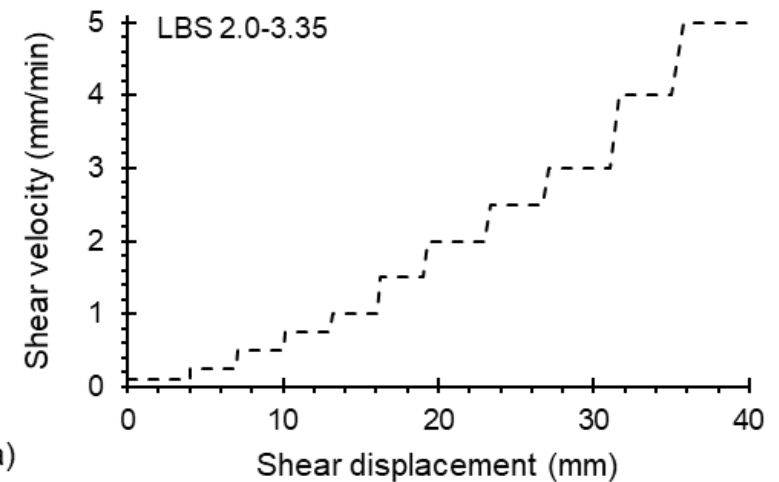

(a)

Shear displacement $(\mathrm{mm})$

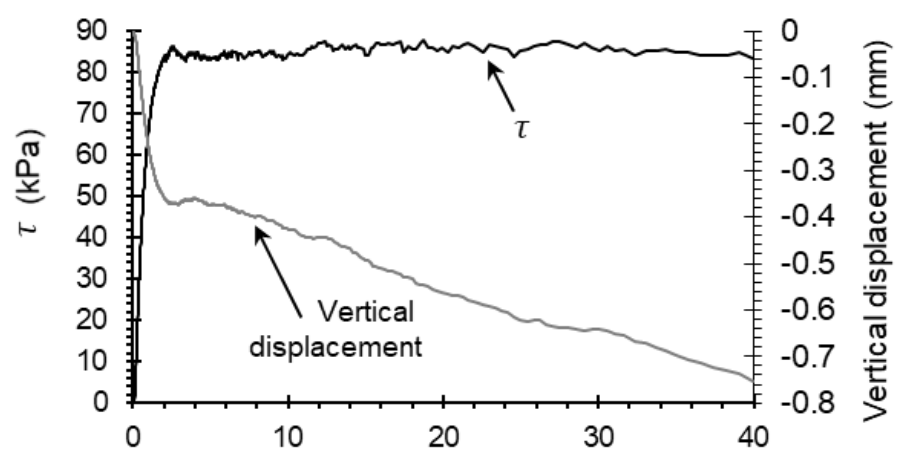

(b)

Shear displacement $(\mathrm{mm})$

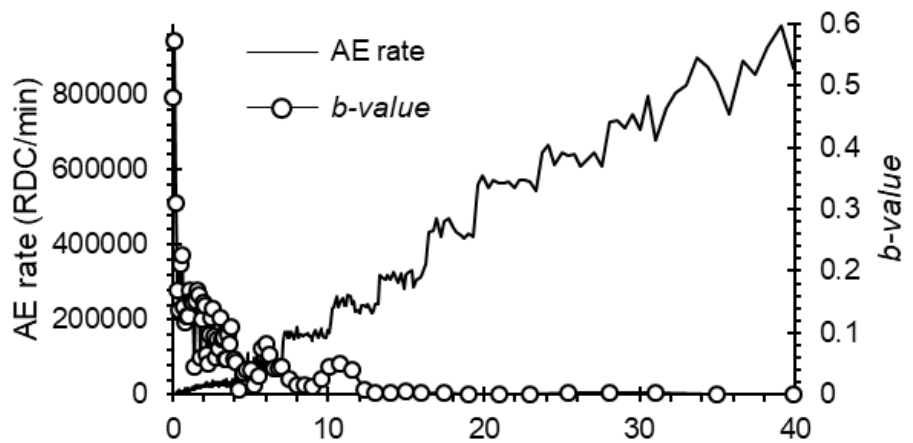

(c)

Shear displacement $(\mathrm{mm})$

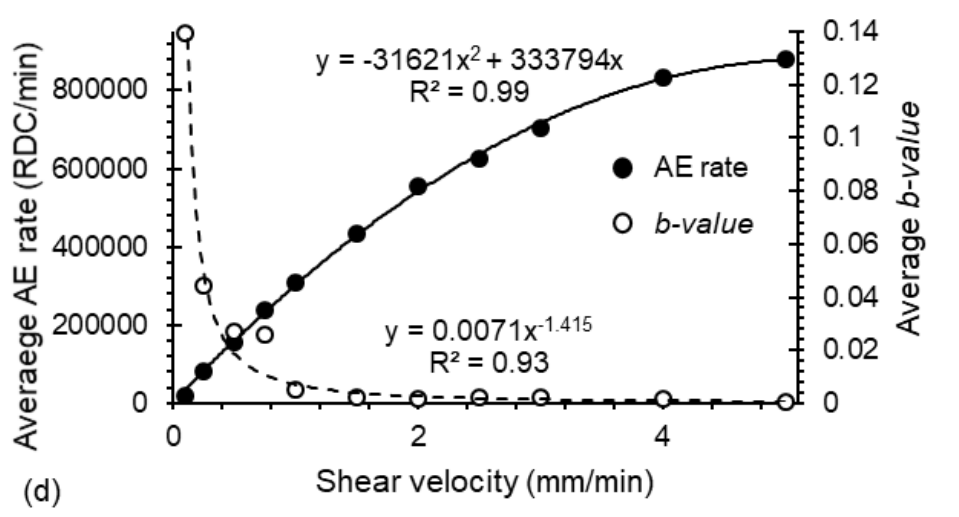

Figure 8. Results from an accelerating shear displacement rate test performed on LBS 2.0-3.35 (test 13) under a constant normal effective stress of $150 \mathrm{kPa}$ : (a) shear velocity plotted against shear displacement; (b) shear stress and vertical displacement (settlement is shown as negative) plotted against shear displacement; (c) AE rate and $b$-value measurements plotted against shear displacement; and (d) average AE and average $b$-value plotted against shear velocity in each test stage 


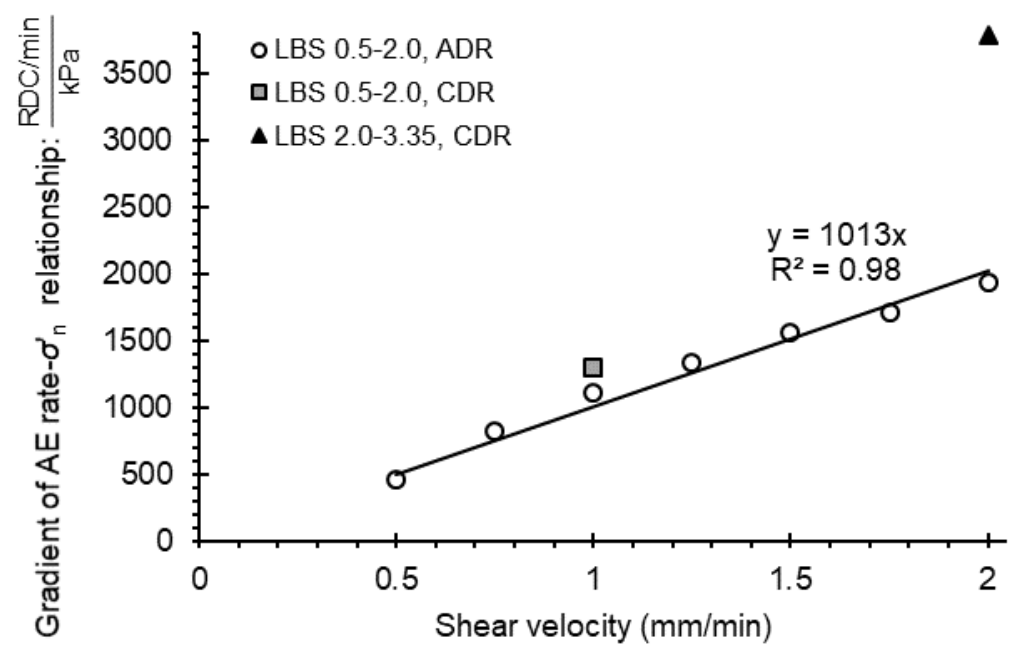

Figure 9. Gradient of $A E$ rate-normal effective stress relationships plotted against shear velocity. The gradient of the LBS 2.0-3.35 (CDR) linear AE rate-normal effective stress relationship was calculated from tests 9-12 (i.e. the gradient reported in Figure 7e), the gradient of the LBS 0.5-2.0 (CDR) linear AE rate-normal effective stress relationship was calculated from tests $1-3$, and the gradients for LBS 0.5-2.0 (ADR) were calculated from tests 4-6 


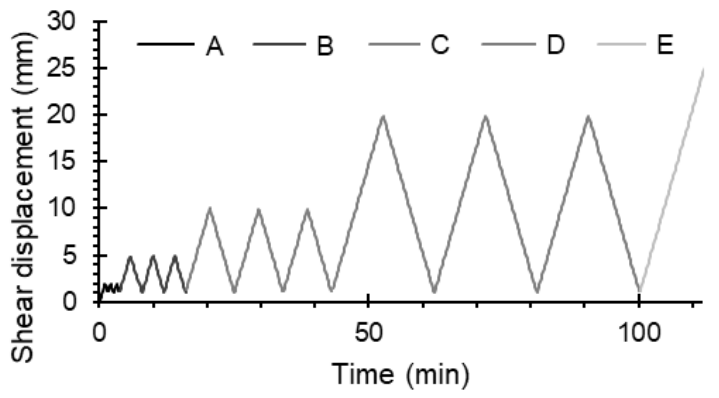

(a)

Time (min)

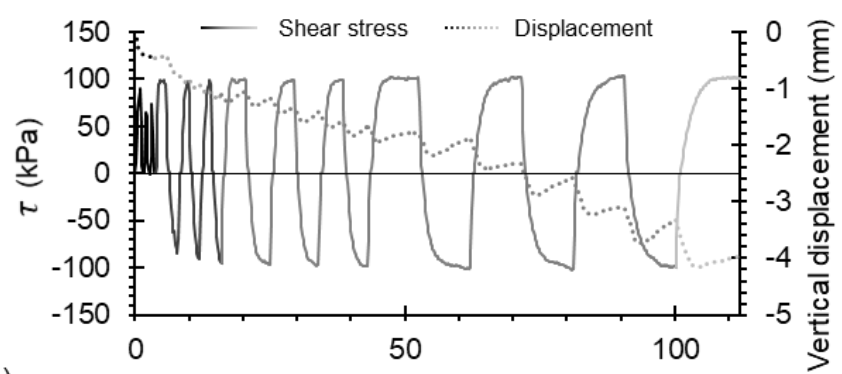

(b)

Time $(\min )$

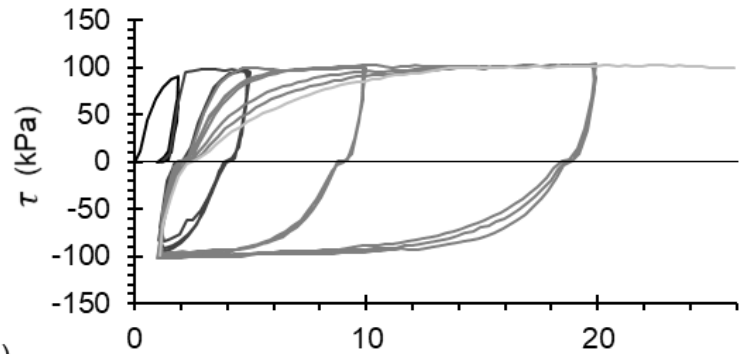

(c)

Shear displacement $(\mathrm{mm})$

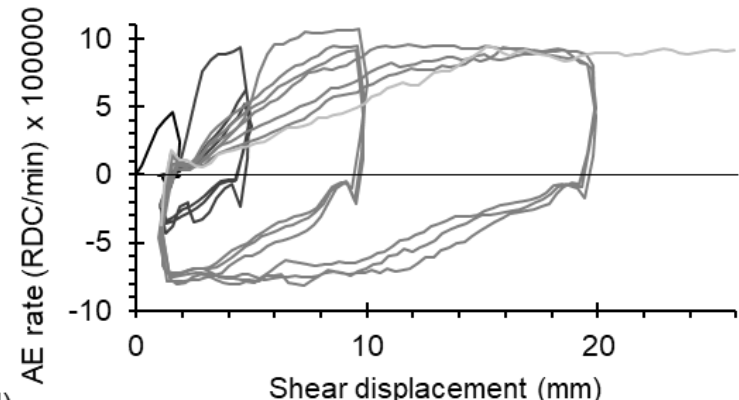

(d)

Shear displacement $(\mathrm{mm})$

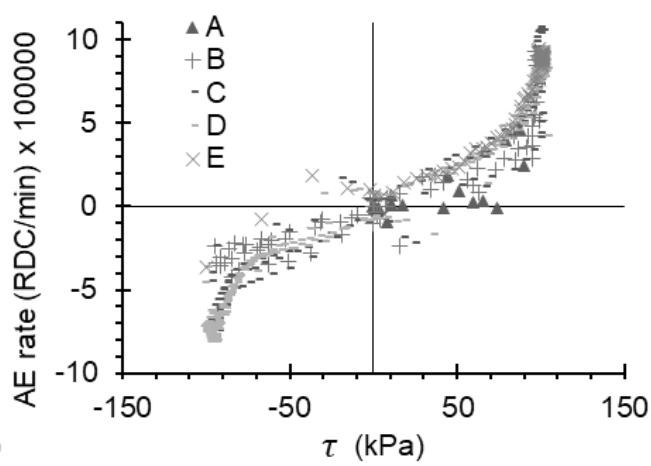

Figure 10. Results from shear displacement cycles performed on LBS 2.0-3.35 (test 14) under a constant normal effective stress of $150 \mathrm{kPa}$ : (a) shear displacement plotted against time; (b) shear stress and vertical displacement (settlement is shown as negative) plotted against time; (c) shear stress plotted against shear displacement; (d) AE rate plotted against shear displacement; and (e) $A E$ rate plotted against shear stress. A, B, C, D and $E$ relate to shearing displacement cycle amplitudes of $1,4,9,19$ and $27 \mathrm{~mm}$, respectively 

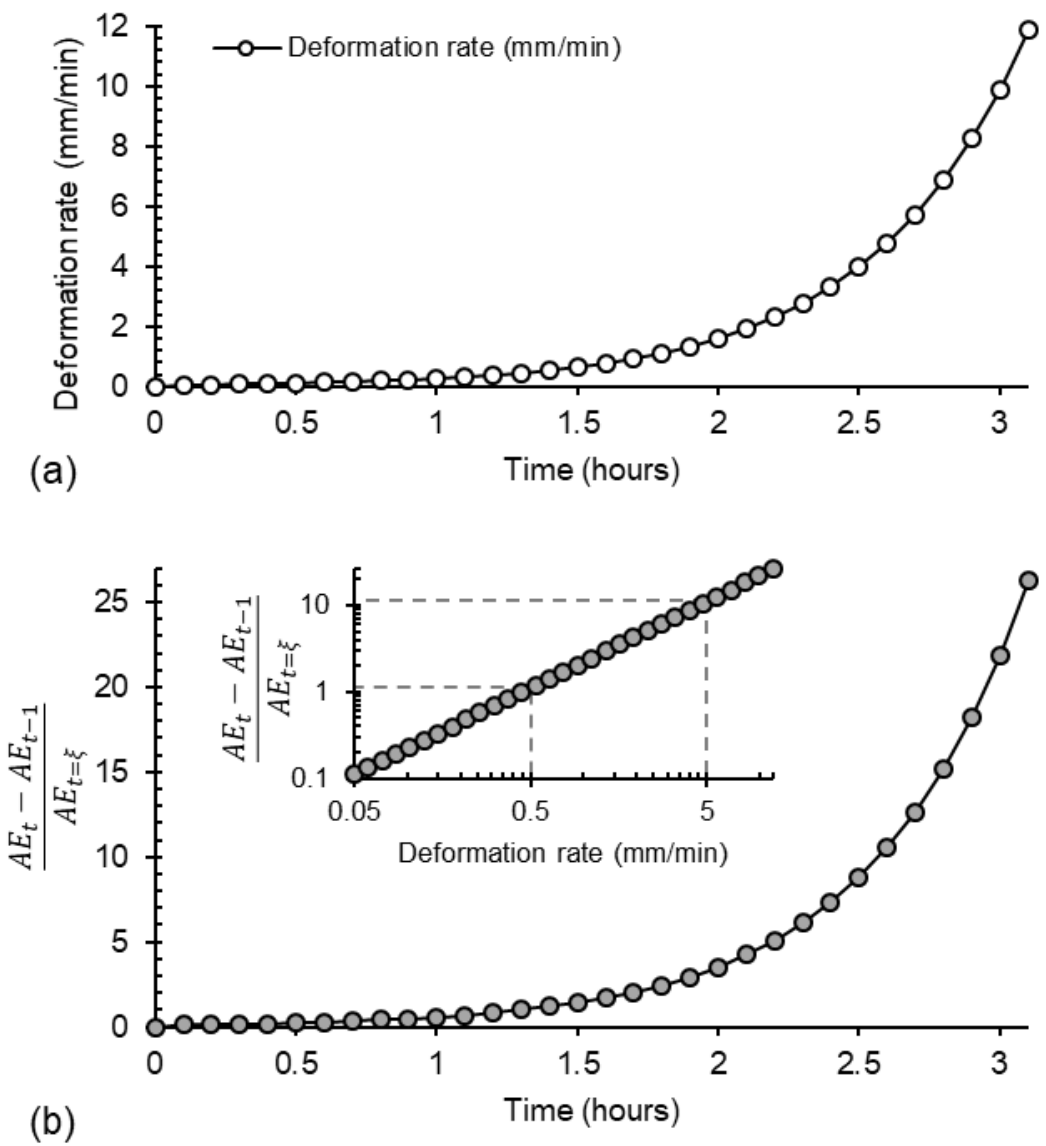

Figure 11. Example use of $A E$ for interpreting accelerating soil/steel deformation behaviour. The example uses the $A E$ rate versus shear velocity relationship shown in Figure 8d. (a) Deformation rate versus time for an illustrative progressive failure event, and (b) normalised $A E$ rate versus time and the insert shows normalised $\mathrm{AE}$ rate versus deformation rate 